\title{
The Mediating Role of Employee Performance on the Relationship between Delegation of
} Authority and Decision Making

\author{
Adnan Alhosani ${ }^{1}$, Rosman Md Yusoff2, Fadillah Ismail ${ }^{3}$, Fazal ur Rehman*1 \\ 1,3FPTP, Universiti Tun Hussein Onn Malaysia, Parit Raja, Johor, Malaysia \\ 2PPUK, Universiti Tun Hussein Onn Malaysia, Parit Raja, Johor, Malaysia \\ fazal_marwatpk@yahoo.com
}

\begin{abstract}
The aim of this study is to enhance understanding in the animated extent of delegation authority and its role in decision making. Precisely, the prime objective of this study is to visualize the concept and propose the effects of delegation authority on decision making along with the mediating role of employees' performance in the Police department at Dubai. Based on an inclusive and systematic literature review of delegation authority, decision making, and employee's performance, this study will collect data through self-administered questionnaires based survey in a quantitative manner. The collected data will be analyzed through smart partial least square structure equation modelling for validating the model, testing hypothesis, and finding results. This study will highlight some new insights into the relevant knowledge area. Specifically, the results will contribute to enhance the motivational synergy of upper management to include the employees in decision-making process to improve their performance. This study is only limited to the police department of Dubai and future studies can examine the relationship between defined constructs in other service sector and the moderating role of employees' performance. By integrating delegation authority, decision making, and employee's performance literature, the prime contributions of this study are the analysis of defined variables in the police department of Dubai with emphasize on new challenges and to boost up the gap of relevant literature.
\end{abstract}

\section{Keywords: Delegation of Authority, Employee Performance, Decision Making Strategy, Management}

\section{Introduction}

In the modern era, the decision-making process has shown significant growth in academic research and organizational practices around the world. Due to the advancement in information, communication, and organizational operations technology, many new challenges take place in organizations on a daily basis. Now, the trend of scientific administration has risen as a new technique to handle the issues of organizational operations and achieve the management objectives. Therefore, for the efficient management planning, operational process, follow-up, implementation, and the activities of the decision-making process, which is like the movement of blood in the human body on eternal basis lead to the conception of delegation authority. It also includes the various levels of management which are considered as a part of administrative work as all the matters either large or small need decisions and its success depends on how its process takes place (Hadi, 2015). Further, it is quite difficult to take part actively in all tasks of management and show efficiency in all decision and can lead to poor performance (Latif, 2015).

The ratio of success of an organization may depend on the capabilities and efficiency of its leadership who take an appropriate decision to achieve its goals and successfully meet the desired objectives in the sense of profitability and development in inner and outer operations. However, the approach and style of leaders to solve the problem may differ from one to other (Walther and Skousen, 2009). The decisionmaking process may be considered as a solution towards the problem as the proper analysis, calendar, prognostication, and extrapolate may be efficient techniques to get a solution (Zimmerman, 2012). However, this study merges the literature of delegation of authority, employee's performance, and decision-making strategies based on the findings in Dubai context and will be a novel contribution. If this study persuades in Dubai police department to examine the role of delegation authority in employees' performance, they can get benefits enormously to improve the security system of Dubai. 


\section{Research Questions}

- Does delegation authority affect decision-making in the police department?

- Does organization functionality affect decision making in the police department?

- Does employees' performance (scientific level, experience and efficiency) mediate the relations of delegation authority and decision-making in the police department?

\section{Research Objectives}

- To determine the impacts of delegation authority on decision making in the police department.

- To determine the impacts of organization functionality on decision making in the police department.

- To determine the mediating role of employees' performance (scientific level, experience and efficiency) between a delegation of authority and decision-making in the police department.

\section{Literature Review}

Developing business in Arabic nations need regular concerns and particular scenery as these nations culturally presents uniqueness and fairly diverse from the Western perspective. Divergences in perspective from others are the comparative beginning age of these nations, as they have solid accentuation on belief, the extraordinary rapid monetary change in the prior 50 years, the ancestral and domestic nature of culture, the enormous part of connections (wasta) in working together as their environment in both the nations and its associations, have impact on the current industry situation (Ali, 2005; Stephenson, Russell and Edgar, 2010). Beyond the development of the Gulf States, the longstanding governmental and community desires remain in unsatisfied, as the presence of this is the crucial point of the sovereign in these communities (Kamla and Roberts, 2010). Therefore, longstanding influence assemblies stay in place, for instance, the leadership control numerous associations, and yet incorporated at the high-ranking level. The bonding in which the requirement for a Middle Easterner pioneer who can be viewed as "The Solid and Dependable", standing, edible, versatile and fit for execution resolutions - as simple as who can be a leader (Al-Huzem, 2011). Delegation is a law that provides imprecision and expectation to employees and enhances their moral (Iancu, 2012). Meanwhile, it is a 'political and social process,' which requires detailed analysis, and decision making in foreign policy, and at odds with the goal of creating a more unified voice in the world through coherent, more effective, and more visible foreign policy action" (Austermann, 2014). However, it has also noted that the functionality of organization is interlinked with the decision making strategy (LI and Weng, 2017), and called as "Random Authority" in a matrix management system to handle multiple tasks according to the local context and requirements.

Delegation of Authority: Islamic training gratifies front-runners to counsel and look for exhortation before settling on any sort of approach (Al-Huzem, 2011). As an outcome, Arab's leaders most often lean toward the consultative style of administration, where supervisors casually counsel their dependents after they come with resolution. A minor departure from this, is the quasi-counselling style where directors get counsel their subordinates without considering their thoughts and proposals when settling on a resolution. A few investigations have demonstrated that enabling workers to take an interest in basic leadership can prompt increment in inspiration, work execution, and company development such as indicated by Al-Jammal, et al. (2015) that the appointment of supremacy helps the honorable of workers in any association and it makes workers have self-assured and feelings of a place as a major aspect of the makers in the association. Designation of power is an important substance for associations, as per Al-Jammal et al. (2015), designation of power has an effect on an association, on the supervisor and on the team members. They discoursed the effect of the assignment of power on the association which helps in accomplishing upper hand, increment proceeding and in addition viability in undertaking execution. In a similar vein, they have expressed that the appointment of power has decreased the pressure of supervisor, construct participation and develop trust between the leader and the workers 
which inspired staff fulfilment.

In this manner, it reduces physical and intelligent struggles smeared by supervisors on the level of workers, they expressed that assignment of power takes a shot at accomplishing effective strengthening, building elective and authoritative initiative. It influences representative to feel fearlessness and inspiration for magnificence in execution, and on the level of client, the appointment of power addresses the issues of clients quickly, conveying or giving the zero defer because of designation power. Kombo, Obonyo, and Oloko (2014); Kiiza and Picho (2015) have shown that utilization of designation of power can assist workers' capability to be expended, leaders may have the capacity to keep up their activity position and safeguard the way toward encouraging the business undertakings, representatives' faithfulness, and accomplishing execution productivity and it fills in as an approach to help leader in lightening the weight of maintaining the issues of the business.

Organizational Functionality: Associations exist with the motivation behind realizing retrospectives as a gathering that one individual may not able to accomplish a task separately (Tran and Tian, 2013). These days, organizations may locate in the hierarchical structures that best fit the business in which the association works better, its magnitude and situation seem fruitful. Hierarchical structures need to take after clear ways particularly concerning where and how choices in associations are made, with a specific end and goal to achieve the authoritative objectives (Tran and Tian, 2013). A critical point on the director's plan is, in any case, how to adjust and locate the perfect condition for the choice. The decision may lie between finding a choice dedicated to larger amounts in the sequences, when next to nil power is assigned to subordinates, an occurrence is known as domination; or to build the stack of duties and envoi choice energy to dependents from bring down levels in the associations, implying that delegation is established (Jones, 2013).

Employees' Performance: One of the impact of Sheikocray is a restricted correspondence framework among administrators which exist in numerous Middle Eastern associations, where workers' sentiment is not generally tuned in to (Suliman and Abdulla, 2005) as Middle Easterner administration is a little bit outdated in direct correspondence, exchange and fronting the representatives (McLaurin and Mitias, 2008). In relations with Hofstede (Hofstede, 2011), who has described Middle Easterner societies as having a great power distance, as the research reports "in dynamic associations crossover UAE, another sort of relationship grounded in shared trust and regard is rising amongst superiors and supervisees" (Suliman and Al Kathairi, 2013), which could demonstrate that administration measures the strengthening and is a cumulative pound in UAE associations. One of the main points for a business association arrangement is to increase the upper hand and its value. Without the workers releasing their duties, the goals of the associations may not be accomplished. Therefore, worker execution is an essential factor of association objectives. As indicated by Al-Jammal, Al-Khasawpeh and Hamadat (2015), workers "who are occupied with their work and focused on their associations give a critical upper hand including higher efficiency and lower worker turnover". Hence, it is not astounding that a large percentage of the present associations discover approaches to deliver rights and designations to administrative workers. As every business face challenges now a day, followed with the borderless era, the concern on business operation may be difficult for a single handled business operator. Accordingly, there is a requirement for obligations to be stimulated or appointed to their stipulated supervisor who may decrease the amount of work and the burden of the entrepreneurs or directors.

Decision-Making Strategy: According to the findings of (Bloom, Sadun and Van Reenen (2012); Athanasouli and Goujard (2015); and Gur and Bøjrnskov (2016), the community belief has a solid impact on the locus of basic leadership power in a chain of position. In high principle in social orders, there is a propensity to decentralize while in low trust nations centralization of basic leadership process is more typical and defilement is more drilled (Athanasouli and Goujard, 2015). In the presence of high trust, the movement of basic leadership expert from bosses to subordinates may be more probable and fruitful. This may help in solving difficult issues and get successful in completing the assignment (Yukl, 2010). Since numerous researchers such as (Bloom, Sadun and Van Reenen (2012); Athanasouli and Goujard (2015); and Gur and Bøjrnskov (2016) have exhibited how the level of trust in a nation is 
impacting the hierarchical structure and the place of basic leadership in organizations.

Research Framework: Research framework provides the base to operationalize the theoretical concept and examine the relationship between defined constructs. However, this study has designed a framework to interpret the effects of delegation authority and organizational functionality on decision making along with the mediating role of employees' performance. On the basis of the framework, this study has developed the following hypothesis.

H1: Delegation of authority has a positive relationship with decision making in the police department

H2: There is a statistical significant correlation between the eight fields in the police department.

H3: There is a statistical significant difference in the delegation of authority related to variables (Sex, Age, place of living, place of work, and Salary) in the police department

H4: There is a statistically significant difference in decision making related to variables (Sex, Age, place of living, place of work, and salary) in the police department

H5: There is a statistically significant difference in the eight fields related to variables (Functional role, sex, age, place of living, place of work, and salary) in the police department

H6: Employees' performance mediates the relationship between the delegation authority and decisionmaking process in Police Department.

Figure 1: Proposed Research Framework

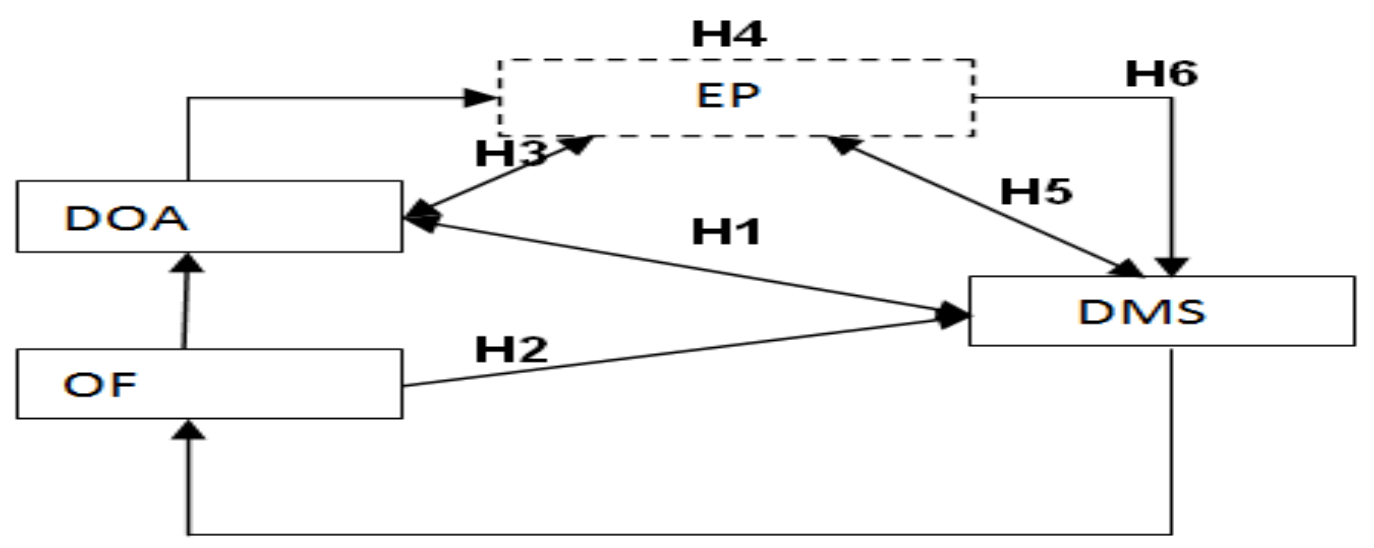

Framework keywords are:

- Employees' Performance: EP,

- Delegation of Authority: DOA,

- Organizational Functionality: OF

- Decision-Making Strategy: DMS

\section{Research Methodology}

The statistical tools in this study resorted to collect data through a questionnaire-based survey among non-mangers in the Dubai police department ( 5 towns). The study questionnaire comprised information about demographic and other main variable of the study. The questionnaire was adopted to collect data. This study has selected a sample size of 750 respondents which consist of managerial and nonmanagerial staff at United Arab Emirates government (Dubai police, who works in (Al-Towara, BrDubai, Al-Rashedia, Gabal-Ali, and Jumeirah). The study will use SPSS, and smart partial least square structure equation modelling to analyze the collected data. 


\section{Results and Discussion}

This study has presented a conceptual framework to examine the impacts of a delegation of authority on the decision-making process along with the mediating role of employees' performance in the police department at Dubai. This study will fill up the gap of knowledge in existing literature by adding new evidence from the police department of Dubai. The results of this study will highlight the degree of delegation of authority in enhancing the employees' performance and decision-making process. However, this study is consistent with the prior studies, such as Al-Jammal, Al-Khasawneh and Hamadat (2015) have examined the impacts of a delegation of authority on employee's performance and noted that delegation of authority has a significant relationship with the efficiency, effectiveness, and empowerment of employee's performance. This study is in line in the sense of delegation authority and its influence on employee's performance. Likewise, Thoms, Idowu and Olarewaju (2018) have assessed the relationship of a delegation of authority with the employee's performance through empirical way and observed that delegation of authority has a significant relationship with the employee's effectiveness. However, Graham, Harvey and Pur (2015) have presumed that delegation of authority toward decision making in firms depends on the nature and structure of firms. The study has explained that the delegation of authority in decision making varies across corporate policies and also depends on the personal characteristics of top management.

Recommendations: Every officer is in charge of observation, measures the execution of its dependents and has a choice of right for smearing corrective measures. As indicated by (Montana and Charnov), this undertaking and decision right for the officer are permitted to turn the workers on posts, to change their KPI's and even to bring down their pay rates if they are not satisfied with their assignments or not meet the activities requirement. By assigning this duty and power delegations to officers, the leader can moderate their workload and let the circumstance be taken care of by the officers closer to the issue who knows the subordinate better (Yukl, 2010). The botch in appointing such power delegation to division officers may influence the execution of the sector, as the supervisor may better understand the workload of his dependent and the level of their capacities. For instance, the inline supervisor better knows the workers' performance in the manufacturing sectors and in the supply chain process. As the uncontrolled and external factors are not visible to top management, thus the inline supervisor has better knowledge about the real situation, and can decide better as compared to top management.

Conclusion: This paper has presented a conceptual framework to examine the influence of delegation of authority in decision making along with the moderating role of employees' performance. Therefore, this study thoroughly read the previous literature to examine what sort of duties and decision power do leaders give to their assistants. In view of the above mentioned previous researchers, it has noted that centralism is more typical and low in belief in many countries. However, numerous studies have clarified that delegation of authority can enhance the level of performance and lead to do the better decision making. The discoveries have demonstrated that authoritative and operational power is not completely assigned from a higher level to bring down at lower levels in the chain of command, supporting that organizations in low trust nations have a central unit resolution, the locus of the resolution being high up in the order. Duties and errands are appointed separately with decision making and in addition, obviously authority powers that include cash, are classified and imperative which can affect the trust in associations negatively. Therefore, a delegation of authority can significantly affect the overall efficiency especially in the police department.

\section{References}

Abd al-Hadi, A. (2015). House of Pharos scientific, Alexandria.

Ali, A. J. (2005). Islamic Perspectives on Management and Organization, Edward Elgar Publishing, Cheltenham.

Al-Huzem, Y. B. U. (2011). The Principles of Leadership, Maktaba Darussalam, Riyadh. 
Al-Jammal, H. R., Al-Khasawneh, A. A. \& Hamadat, M. H. (2015). The impact of the delegation of authority on employees' performance at great Irbid municipality: case study, International Journal of Human Resource Studies, 5(3), 48-69.

Athanasouli, D. \& Goujard, A. (2015). Corruption and Management Practices: Firm Level Evidence. Journal of Comparative Economics, 43(4), 1014-1034.

Austermann, F. (2014). European Union Delegations in EU Foreign Policy, The European Union in International Affairs series.

Bloom, N., Sadun, R. \& Van Reenen, J. (2012). The Organization of Firms across Countries. The Quarterly Journal of Economics, 127(4), 1663-1705.

Graham, J. R., Harvey, C. R. \& Pur, M. (2015). Capital allocation and delegation of decision-making authority within firms, Journal of financial economics, 115, 449-470.

Gur, N. \& Bjørnskov, C. (2016). Trust and Delegation: Theory and Evidence. Journal of Comparative Economics, (000), 1-14.

Hofstede, G. (2001). Culture's Consequences: International Differences in Work-Related Values, 2nd ed., Sage, Beverly Hills.

Iancu, B. (2012). Legislative Delegation, the Erosion of Normative Limits in Modern Constitutionalism.

Jones, G. R. (2013). Organizational Theory, Design and Change. 7th ed. Harlow: Pearson Education Limited.

Kamla, R. \& Roberts, C. (2010). The global and the local: Arabian Gulf States and imagery in annual reports, Accounting, Auditing \& Accountability Journal, 23(4), 449-481.

Kiiza, P. \& Picho, E. O. (2015). Delegation and staff commitment in the school of finance and banking in Kigali, Rwanda: An empirical study. Global Journal of Commerce and Management Perspective, $4(3), 50-54$.

Kombo, B. W., Obonyo, G. O. \& Oloko, M. (2014). Effects of delegation on employee performance in savings and credit cooperative societies in Kisii County, Kenya. The International Journal of Business and Management, 2(7), 22-31.

Latif, A. E. (2015). Delegation of authority, International Neulenk for publication and distribution, Cairo.

LI, S. \& Weng, X. (2017). Random Authority, International Economic Review, 58, 211-235.

McLaurin, J. R. \& Mitias, P. (2008). Transformational strategy in the city of gold: pursuit of the vision, Allied Academies International Conference: Proceedings of the Academy of Strategic Management (ASM), 7(2), 20-24.

Montana, P. \& Charnov, B. (2000). Management. 3rd ed. Hauppauge, N.Y: Barron's.

Stephenson, M. L., Russell, K. A. \& Edgar, D. (2010). Islamic hospitality in the UAE: indigenization of products and human capital, Journal of Islamic Marketing, 1(1), 9-24.

Suliman, A. M. \& Abdulla, M. H. (2005). Towards a high-performance workplace: managing corporate climate and conflict, Management Decision, 43(5), 720-733.

Suliman, A. \& Al Kathairi, M. A. (2013). Organizational justice, commitment and performance in developing countries: the case of the UAE, Employee Relations, 35(1), 98-115.

Thomas, 0. 0., Idowu, 0. 0. \& Olarewaju, A. A. (2018). Delegation of authority and Employees Performance: An Empirical Evidence from Ikeja Division in Lagos State, Lagos State University, retrieved from: http://jei.uni-ruse.bg/Issue-2016/08.\%200lajide_Okunbanjo_Adeoye.pdf, Accessed on 12/21/2018.

Tran, Q. \& Tian, Y. (2013). Organizational Structure: Influencing Factors and Impact on a Firm. American Journal of Industrial and Business Management, 3(2), 229-236.

Walther, L. M. \& Skousen, C. J. (2009). Budgeting and decision making, London business school, United Kingdom.

Yukl, G. (2010). Leadership in Organizations. 7th ed. New Jersey: Pearson.

Zimmerman, P. B. (2012). Decision-Making for Leaders, Advanced Leadership Initiative at Harvard University. 